\title{
intersubjetividade: um olhar sobre a comunidade de investigação filosófica ${ }^{1}$
}

\author{
paula alexandra vieira ${ }^{2}$ \\ universidade dos açores - nica \\ escola básica e secundária armando côrtes-rodrigues, portugal \\ orcid id: https:/ / orcid.org/0000-0003-1856-1765
}

\section{resumo}

O paradigma da intersubjetividade preconizado por Jürgen Habermas fundou uma forma de chegar a consensos racionalmente fundamentados. A sua obra aponta para a ideia de que o que mantém as pessoas numa atitude de ação comunicativa são as forças da fundamentação racional e da motivação racional. Ao analisarmos a dimensão intersubjetiva da prática da comunidade de investigação filosófica, demo-nos conta de que é possível verificar a passagem de uma autonomia da razão centrada no sujeito (um pensar por si mesmo), para a prática de uma racionalidade comunicativa (centrada num pensamento em comunidade). Os pressupostos inevitáveis da comunicação fundam e mantêm as comunidades e permitem o clima de confiança e de cuidado que possibilita que os membros da comunidade pensem livremente e se deixem guiar pela força do we, do nós, do nos-otros. Não é somente em contexto de comunidades de investigação filosófica que se verificam as potencialidades do paradigma da intersubjetividade de Habermas. Também na discussão entre especialistas podemos encontrar essas potencialidades. Foi, em certa medida, este o rasto que conseguimos traçar ao investigarmos as diferentes abordagens de Ann Sharp, David Kennedy e Giuseppe Ferraro sobre a noção de comunidade de investigação filosófica. O diálogo estabelecido entre estes filósofos e o conceito de comunidade de investigação filosófica, os seus argumentos e as formas de concretização do diálogo filosófico em comunidade, dão conta da fecundidade da racionalidade comunicativa. Sabemos que o conceito de comunidade de investigação filosófica, tal como é pensado e vivido por Ann Sharp, é distinto do conceito de comunidade de investigação filosófica de David Kennedy. Percebemos que o círculo do pensar de Giuseppe Ferraro é uma outra abordagem ao pensamento filosófico em comunidade. No entanto, na nossa investigação estas abordagens entraram em diálogo e, em boa medida, devido ao que é permitido pelo próprio movimento de uma racionalidade comunicativa. Estas possibilidades de diálogo dão-se no pressuposto de uma relação intersubjetiva também entre conceitos, experiências e pensamento sobre os conceitos e as experiências. $\mathrm{O}$ caminho percorrido entre a comunidade de investigação filosófica entendida como espaço de intersubjetividade (Sharp, 1987), passando pela abertura da comunidade de investigação filosófica a outras dimensões não discursivas da comunicação (Kennedy, 1994) e avançando para o círculo do pensar que enche o espaço de tempo e o torna num lugar (Ferraro, 2018) revela como a comunidade de investigação filosófica é um conceito e uma experiência abertos e fecundos: um conceito em ação.

palavras-chave: intersubjetividade; racionalidade comunicativa; comunidade de investigação filosófica.

\section{intersubjectivity: a look at the community of philosophical inquiry}

\begin{abstract}
The intersubjective paradigm advocated by Habermas laid the foundation for a new way of reaching rationally predicated consensus. His work indicates that what keeps people in an attitude of communicative action is rational basis and motivation. Upon analysing the intersubjective dimension of the practice of the community of philosophical inquiry, we realized that it possible to observe the transition from a subject-centred autonomy of treason (thinking for oneself), to the practice of a communicative rationality (focused on thinking in community). The inevitable assumptions of communication ground and sustain communities and allow for an environment of

1 Texto Ganhador da edição de 2019 do Prêmio ICPIC à Excelência em interpretar Filosofia para/com crianças, outorgado pelo Conselho Internacional para a Investigação Filosófica com Crianças.

2 E-mail: philospaula@hotmail.com
\end{abstract}


trust and care that enables community members to think freely and let themselves be driven by the power of "we", "nos-otros". It is not only in the context of communities of philosophical inquiry that the potential of Habermas' intersubjective paradigm can be observed, but also in the discussion among specialists. To an extent, this is what we found when we studied the various approaches of Ann Sharp, David Kennedy, and Giuseppe Ferraro to the concept of the community of philosophical inquiry. The dialogue between these philosophers and the concept of the community of philosophical inquiry, their arguments, and the ways of achieving philosophical dialogue in community offer rich evidence of the productiveness of communicative rationality. We are aware that Ann Sharp's concept of community of philosophical inquiry is different from David Kennedy's, and that both are distinct from Giuseppe Ferraro's circle of thinking. Nevertheless, we place these different approaches into dialogue, due largely to what is permitted by the movement of communicative rationality itself. These possibilities for dialogue are also grounded in the assumption of an intersubjective relationship between concepts, experiences and thoughts about concepts and experiences. By understanding the community of philosophical inquiry as a space of intersubjectivity (Sharp, 1987), opening the philosophical community to other non-discursive dimensions of communication (Kennedy, 1994), and analysing the circle of thinking that fills space with time and turns it into a place (Ferraro, 2018), we reveal that the community of philosophical inquiry is an open and fruitful concept and experience: a concept in motion.

keywords: intersubjectivity; communicative rationality; community of philosophical inquiry.

\section{intersubjetividad: un mirar sobre la comunidad de investigación filosófica}

\section{resumen}

El paradigma de la intersubjetividad profesado por Jürgen Habermas fundó una forma de llegar a consensos racionalmente fundamentados. Su obra apunta a la idea de que lo que mantiene a las personas en una actitud de acción comunicativa son las fuerzas de la fundamentación racional y de la motivación racional. Al analizar la dimensión intersubjetiva de la práctica de la comunidad de investigación filosófica, nos damos cuenta que es posible verificar el pasaje de una autonomía de la razón centrada en el sujeto (un pensar por sí mismo), a la práctica de una racionalidad comunicativa (centrada en un pensamiento en comunidad). Los presupuestos inevitables de la comunicación fundan y mantienen las comunidades y permiten el clima de confianza y de cuidado que posibilita que los miembros de la comunidad piensen libremente y se dejen guiar por la fuerza del we, del nós, del nos-otros. No es solamente en contexto de comunidades de investigación filosófica que se verifican las potencialidades del paradigma de la intersubjetividad de Habermas. También en la discusión entre especialistas podemos encontrar esas potencialidades. Fue, en cierta medida, este rastro el que conseguimos trazar al investigar los diferentes abordajes de Ann Sharp, David Kennedy y Giuseppe Ferraro sobre la noción de comunidad de investigación filosófica. El diálogo establecido entre estos filósofos y el concepto de comunidad de investigación filosófica, sus argumentos y las formas de concreción del diálogo filosófico en comunidad, dan cuenta de la fecundidad de la racionalidad comunicativa. Sabemos que el concepto de comunidad de investigación filosófica, tal como es pensado y vivido por Ann Sharp, es distinto del concepto de comunidad de investigación filosófica de David Kennedy. Entendemos que el círculo del pensar de Giuseppe Ferraro es un otro abordaje al pensamiento filosófico en comunidad. Sin embargo, en nuestra investigación estos abordajes entraron en diálogo y, en buena medida, debido a lo que es permitido por el propio movimiento de una racionalidad comunicativa. Estas posibilidades de diálogo se dan en el presupuesto de una relación intersubjetiva también entre conceptos, experiencias y pensamiento sobre los conceptos y las experiencias. El camino recorrido entre la comunidad de investigación filosófica entendida como espacio de intersubjetividad (Sharp, 1987), pasando por la apertura de la comunidad de investigación filosófica a otras dimensiones no discursivas de la comunicación (Kennedy, 1994) y avanzando hacia el círculo del pensar que llena el espacio de tiempo y lo convierte en un lugar (Ferraro, 2018) revela cómo la comunidad de investigación filosófica es un concepto y una experiencia abiertos y fecundos: un concepto en acción.

palabras clave: intersubjetividad; racionalidad comunicativa; comunidad de investigación filosófica. 
intersubjetividade: um olhar sobre a comunidade de investigação filosófica

Tive uma ideia e fiz com ela o que pude. (Matthew Lipman, 2011, p. 198)

O texto que apresentamos ${ }^{3}$ tem dois objetivos: (1) esclarecer o conceito de intersubjetividade de acordo com o pensamento de Jürgen Habermas, realçando aquilo que nele nos parece trazer alguma luz ou novos olhares à prática de comunidade de investigação filosófica; (2) estabelecer algumas possibilidades de diálogo entre esta noção de intersubjetividade e a noção de comunidade de investigação filosófica, tal como é pensada por Ann Sharp, David Kennedy e Giuseppe Ferraro. Sempre que nos parecer relevante, far-se-á referência a falas das crianças registadas ao longo das nossas práticas de comunidade de investigação filosófica nos últimos quatro anos ${ }^{4}$.

Tem sido a nossa intenção pensar a comunidade de investigação filosófica à luz do paradigma da intersubjetividade de Jürgen Habermas. É um caminho teóricoprático entre os conceitos de intersubjetividade e comunidade de investigação filosófica e a prática de sessões de filosofia para crianças ${ }^{5}$. Esta investigação surge de duas questões que, apesar de diferentes, se complementam: $\mathrm{O}$ que é pensar por si mesmo? Que motivos levarão alguém a abdicar da supremacia razão autónoma em favor do primado de uma razão comunicativa e intercomunicativa?

3 Encontramo-nos a preparar uma dissertação de Mestrado em Filosofia para Crianças na Universidade dos Açores e as reflexões que partilhamos no presente texto foram produzidas nesse contexto. Não constituem uma parte específica da dissertação, mas dão conta de alguns caminhos paralelos de investigação que fomos percorremos no âmbito das perguntas que o pensamento nos foi colocando.

${ }^{4}$ No contorno das nossas atividades docentes, coordenamos um projeto de filosofia para crianças que começou no ano escolar de 2014/2015, na Escola Básica e Secundária Armando CôrtesRodrigues em Vila Franca do Campo, São Miguel, Açores. No presente ano letivo (2018/2019), participam no projeto 480 crianças, entre os 4 e os 12 anos, num total de 28 turmas, com sessões regulares semanais e continuadas de atividades em comunidade de investigação filosófica. $\mathrm{O}$ projeto envolve 28 docentes regulares das turmas, de diferentes áreas disciplinares, e 3 professores facilitadores com formação inicial em filosofia (licenciatura) e formação pós-graduada em filosofia para crianças Para além das sessões regulares nas turmas, por vezes acontecem sessões em comunidades de diálogo entre crianças e adolescentes. Agradecemos aos membros das comunidades de investigação filosófica com os quais trabalhamos o contributo e as ideias a que nos referimos no texto, bem como as provocações de pensamento. Os nomes das crianças são fictícios e todos os elementos passíveis de as identificar foram alterados para proteção da sua privacidade.

5 Com a designação "filosofia para crianças" referimo-nos a uma área filosófica que engloba a problematização dos diferentes aspetos (epistemológicos, éticos, estéticos, políticos, sociais, entre outros) em causa no trabalho da prática filosófica do diálogo em comunidade de investigação que envolve pessoas de diferentes idades em ambientes formativos, incluindo sobretudo crianças. 
intersubjetividade: um olhar sobre a comunidade de investigação filosófica

Assim, pretendemos dar conta da reflexão acerca da dimensão intersubjetiva na prática filosófica com crianças de acordo com a abordagem da comunidade de investigação filosófica, cujo ambiente de confiança e investigação inaugura um espaço no qual se identifica e decide como viver melhor de acordo com uma atitude de abertura às razões dos outros (SHARP, 1987, sublinhado nosso). Trata-se, por isso, de um espaço de intersubjetividade, acrescenta Ann Sharp, uma das fundadoras da Filosofia para Crianças.

A filosofia para crianças começou como um programa de filosofia prática na década de 70 do século passado, nos EUA, com os trabalhos de Matthew Lipman e Ann Sharp. Algumas décadas mais tarde, autonomizou-se desse programa e atualmente constitui um movimento (VANSIELEGHEM \& KENNEDY, 2011) que congrega diferentes especialistas e praticantes em torno da ideia de juntar a filosofia e as crianças.

De acordo com a nossa posição e leitura desse movimento, a filosofia para crianças pressupõe a construção de comunidades de investigação filosófica constituídas pelas crianças que participam no diálogo e pelos adultos que o facilitam (SPLITTER \& SHARP, 1995). Segundo esta abordagem, o pensamento promovido nas comunidades de investigação filosófica entende-se como multidimensional, isto é, um pensamento crítico (critical), criativo (creative) e de cuidado (caring) (LIPMAN, 2003).

Pensada, repensada e aprofundada após a obra de M. Lipman e A. Sharp, a noção de comunidade de investigação filosófica tem sido vista como uma comunidade intencional de discurso num grupo de pessoas que regularmente se encontram para dialogarem sobre conceitos e problemáticas de natureza filosófica, como é o caso de ideias centrais e contestáveis como verdade, justiça, amizade, tempo... (KENNEDY \& KENNEDY, 2012). Guiseppe Ferraro refere-se às comunidades de diálogo filosófico como um círculo do pensar, um lugar de relação ou, dito de outro modo, um espaço cheio de tempo, instituindo um campo didático, uma relação ensinante onde se troca, se doa, se restitui tempo (2018, p. 28-29, sublinhado nosso).

As diferentes aproximações ao conceito de comunidade de investigação filosófica dos autores escolhidos, como veremos mais adiante, sugerem a potencialidade do conceito e demonstram, em certa medida, o que acontece 
quando se lança uma ideia à discussão e se tem a possibilidade de a investigar em comunidade. É da discussão entre as obras destes especialistas que, nas últimas décadas, têm sido apresentados diferentes rumos para o conceito de comunidade de investigação filosófica, permitindo potencializar práticas que consideramos irem ao encontro das pressuposições inevitáveis da comunicação de Habermas. Seguindo esta orientação, consideramos que na comunidade de investigação as ideias são lançadas em discussão no que se poderia considerar uma prática de racionalidade comunicativa.

De facto, Habermas considera que há uma disposição cooperativa para o entendimento e que daqui decorre que a razão autónoma centrada no sujeito pode dar lugar a uma racionalidade comunicativa assente em pressuposições inevitáveis da comunicação, cujos postulados trazem consigo a forças $d a$ fundamentação racional e da motivação racional (HABERMAS, 2010). Assim, podemos pensar que estes conceitos habermasianos contribuem para a fundação e a manutenção da noção e da prática de comunidades de investigação filosófica ${ }^{6}$.

Dividiremos a nossa reflexão em duas partes: na primeira, ocupar-nos-emos do conceito de intersubjetividade e, na segunda, procuraremos enunciar e explorar as ligações que entrevemos entre a noção de comunidade de investigação filosófica e intersubjetividade.

\section{intersubjetividade}

A intersubjetividade é a proposta do filósofo alemão Jürgen Habermas para a saída da filosofia do sujeito, que foi construída ao longo do discurso filosófico da modernidade (HABERMAS, 1985). A filosofia do sujeito é entendida por Habermas como "aquela atitude objetivante em que sujeito cognoscente se dirige a si mesmo como a entidades no mundo" (1985, p. 414).

\footnotetext{
${ }^{6}$ No espectro da literatura de especialidade da Filosofia para Crianças, deparamo-nos com afirmações segundo as quais a Filosofia para Crianças é um programa que se encontra intimamente relacionado com o pensamento de autores como Habermas (FLETCHER, 2016) e que as comunidades de investigação filosófica são situações reais de ação comunicativa, de exercício de uma racionalidade comunicativa (WEBER, 2008). Tomás Miranda Alonso (1991) afirma que no programa de Filosofia para Crianças de Lipman, a ideia de que a sala de aula se possa transformar numa comunidade de investigação e busca cooperativa para a verdade é um exemplo do que Habermas entendia como uma ação comunicativa orientada para o entendimento.
} 
intersubjetividade: um olhar sobre a comunidade de investigação filosófica

O discurso filosófico da modernidade revelara uma racionalidade desencantada com o religioso e voltada para uma cultura profana e incrementara a liberdade individual, do conhecimento e do mundo, num ilimitado número de argumentos e posições instrumentalistas. Tratou-se de uma época fundada sobre a autonomia da razão e que possibilitou uma filosofia do sujeito.

Neste contexto, Habermas afirma que "o paradigma do conhecimento do objeto tem de ser substituído pelo paradigma da compreensão mútua entre sujeitos capazes de falar e agir" (HABERMAS, 1985, p. 276) e coloca em diálogo a autonomia de uma razão centrada no sujeito e uma nova leitura da razão, de feição comunicativa e intersubjetiva. Trata-se de um paradigma da intercompreensão de onde emerge uma atitude através da qual os interlocutores em interação promovem acordos sobre algo do mundo e coordenam planos de ação a partir destes acordos.

No paradigma da intersubjetividade habermasiano, o que está em causa é "uma disposição cooperativa para o entendimento" (HABERMAS, 2010, p. 185). O filósofo assume que há um interesse genuíno para o entendimento que se revela, entre outras, na linguagem e na comunicação entre os sujeitos. $O$ paradigma da intersubjetividade assenta, então, numa razão dialogante por intermédio do discurso e da busca da pretensão de validade dos atos de fala: uma racionalidade comunicativa (HABERMAS, 1985). A racionalidade habermasiana é entendida como uma capacidade de justificar crenças e ações, de encontrar critérios no procedimento argumentativo e a sua força consiste na coesão da compreensão intersubjetiva e do reconhecimento mútuo. A racionalidade comunicativa presume a aptidão de participantes em interação se orientarem para relações de exigência de validade que supõe um reconhecimento intersubjetivo.

Neste quadro teórico, Habermas (2010) afirma que a intersubjetividade é uma estrutura argumentativa suficiente para conduzir a decisões racionalmente fundamentadas sobre pretensões de validade, quer teóricas quer práticas, e que exige que se passem de afirmações problematizadas (ações) a afirmações cuja pretensão de validade se tornem o objeto de discurso (factos). A explicação teórica da afirmação problematizada é acompanhada de razões entendidas, compreendidas e discutidas pelos participantes na comunidade, podendo dar-se a 
modificação do sistema linguístico escolhido com recurso à ponderação acerca de sistemas alternativos. Trata-se de uma radicalização ulterior, uma reflexão sobre alterações sistemáticas das linguagens justificativas - uma mudança de paradigma. O discurso, o discorrer da razão em sede de linguagem, é uma vertente da comunicação que pergunta pela legitimidade da pretensão de validade.

Segundo Habermas, razão comunicativa e ação comunicativa são dois conceitos diferentes mas fortemente ligados. A racionalidade comunicativa baseiase na noção de ação comunicativa - ação orientada para o entendimento intersubjetivo - e nas pressuposições inevitáveis da ação comunicativa ou da comunicação humana como, por exemplo, só conta a força do melhor argumento e nada está imune à crítica (HABERMAS, 1986). O recurso à experiência das coisas para apoiar a pretensão de validade das afirmações não é, por isso, suficiente. Torna-se necessário dizer, argumentar, o que implica um certo distanciamento dos contextos da ação e da experiência (HABERMAS, 2010).

Já a ação comunicativa é um modo de coordenação da ação na vida concreta e na sua reprodução. Através da distinção entre ação comunicativa e ação estratégica (COOKE, 1994), Habermas sublinha que a ação comunicativa é o modo primário de coordenação da ação na vida concreta através de consensos, próprios da ação comunicativa (HABERMAS, 1996). Os consensos são mecanismos de coordenação social conectados com as ideias de compreensão linguística e a busca para chegar a acordos. Trata-se do movimento que parte da compreensão para chegar ao acordo com base numa pragmática da linguagem conhecida e partilhada. Isto pressupõe que o uso da linguagem orientada para o consenso desenvolva nos interlocutores uma visão do mundo descentrada, que possibilite aos participantes em comunicação, isto é aos interlocutores no processo de entendimento, assumirem novas aberturas ao mundo dos factos, a uma relação normativa com o mundo social e a uma atitude expressiva concernente à relação com o mundo subjetivo da experiência interior (COOKE, 1994, p. 10).

A tese de Habermas é que com a autonomia da razão centrada no sujeito presente nos discursos filosóficos da modernidade, os interlocutores desenvolvem a capacidade de distinguir diferentes dimensões de validade como, por exemplo, 
intersubjetividade: um olhar sobre a comunidade de investigação filosófica

reconhecer que a validade da afirmação "está a chover lá fora" exige metodologias e procedimentos diferentes das que reconhece a validade de afirmações como "estou com dor de cabeça" e "o aborto é moralmente errado". Com o pensamento de Habermas, outras dimensões de racionalidade são postuladas, isto é, a abertura a diferentes atitudes possibilita uma relação reflexiva com o mundo em diferentes dimensões.

Neste modo da ação comunicativa, o interlocutor relativiza o seu enunciado face à possibilidade de ser contestado pelos seus interlocutores com base em razões. É neste sentido que a ação comunicativa é orientada para o entendimento mútuo: "chegar a um entendimento é o processo de dar origem a uma concordância segundo a base pressuposta de pretensões de validade que sejam mutuamente reconhecidas" (HABERMAS, 1996, p. 13).

Os interlocutores em ação comunicativa asseguram, simultaneamente, as relações entre as suas vidas e partilham intersubjetivamente um mundo de vida. As fronteiras do mundo de vida são a totalidade das interpretações e suposições que os membros da comunidade partilham e entendem como conhecimento de base. Assim, os membros da comunidade orientam as suas ações de acordo com critérios de validade intersubjetivos e um crescente grau de racionalidade comunicativa conduz à possibilidade de um sem número de ações coordenadas e de resolução consensual de conflitos. Neste modelo, as expressões racionais têm um carácter de dar sentido, permitir uma inteligibilidade ao contexto e do contexto. Cada participante atinge os seus objetivos somente de uma forma colaborativa. O sucesso não é individual mas em cooperação com os outros.

Habermas (1989) afirma que a ação comunicativa é uma situação ideal de fala, uma forma de "bitola crítica" para avaliar se qualquer consenso alcançado se trata ou não de um consenso racionalmente fundamentado. As condições da situação ideal de fala conduzem para a centralidade do discurso e possibilidade de consensos racionais fundamentados pela força da argumentação, isto é, a força do melhor argumento.

O uso da expressão situação ideal de fala levou a mal entendidos na hermenêutica habermasiana que o próprio autor procurou esclarecer. Na verdade, a referência a um ideal traz em si a ideia que uma situação ideal de fala é uma 
construção enquadrada pelos limites espácio temporais do processo comunicativo e está sujeita a resistências psíquicas. Pode ser uma miragem. Poderemos nunca ter a certeza de que não nos iludimos quando julgamos participar num discurso. Nesse sentido, Habermas (2008) substituiu a expressão situação ideal de fala pela expressão pressupostos inevitáveis da prática argumentativa. O filósofo afirma que “(...) esses pressupostos inevitáveis da prática argumentativa não são de modo algum meros constructos. Pelo contrário, eles são realmente eficazes no comportamento dos próprios participantes. Alguém que participa seriamente de um argumento procede de facto de tais pressuposições" (HABERMAS, 2008, p. 51).

O consenso de fundo acerca da pretensão de validade é um reconhecimento de interlocutores competentes em quatro dimensões: compreensibilidade, sinceridade, correção e verdade de enunciados (HABERMAS, 2010). As pressuposições idealizadoras da comunicação baseiam-se no postulado da igualdade discursiva que possibilita a força da fundamentação racional, isto é, todos os participantes têm de ter a mesma oportunidade de aventarem interpretações, explicações, justificações, rebaterem declarações e mudarem as respetivas pretensões de validade. Nenhuma opinião formada pode ser subtraída à crítica. Acrescenta-se, ainda, o postulado da sinceridade que possibilita a força da motivação racional, isto é, todos os participantes têm iguais oportunidades de atos de fala representativos, expressar atitudes, sentimentos e desejos, de serem sinceros consigo próprios de modo a que "tornem transparente a sua natureza interior" (HABERMAS, 2010).

A prática de uma racionalidade comunicativa em substituição de uma racionalidade autónoma centrada no sujeito abre a possibilidade lançar o pensar por si mesmo ao pensar em comunidade. As comunidades de investigação filosófica podem ser olhadas como espaços intersubjetivos, lugares de "disposição genuínas para o entendimento" regidas pelos postulados da sinceridade e da igualdade discursiva. 
intersubjetividade: um olhar sobre a comunidade de investigação filosófica

\section{comunidade de investigação filosófica e intersubjetividade}

Pensar por si mesmo e pensar com os outros sugere, à primeira vista, que se tratam de atividades diferentes e até opostas. Todavia, se tivermos em conta a instauração da racionalidade comunicativa, segundo Habermas, assim como a ideia de que o pensamento próprio se constrói com o pensamento dos outros e que a investigação segue pela mão da comunidade (LIPMAN, 2003), percebemos que o pensar por si mesmo e o pensar com os outros não constituem uma dicotomia.

Pensar com os outros é uma forma de pensar por si mesmo e também a forma mais eficaz de se pensar bem por si mesmo (LIPMAN, 2003). O pensamento é encarado como um processo de construção e em construção, ao invés de uma adoção de soluções, e essa construção do pensamento e da investigação faz-se em comunidade. Este é um caminho que mobiliza interesses, por exemplo uma disposição cooperativa para o entendimento, e tem motivações intrínsecas, por exemplo as forças da fundamentação racional e da motivação racional. Trata-se de uma relação de confiança e respeito entre os membros da comunidade e os seus interesses, também no que respeita aos próprios procedimentos do pensar. Neste contexto, trata-se de conversas acerca de problemas, vivências, pensamentos, preocupações compartilhadas que levam em conta a perspetiva dos outros. $\mathrm{O}$ diálogo é o eixo central desta ligação que é sempre uma busca de sentido (SPLITTER \& SHARP, 1995).

O diálogo que se constrói numa comunidade de investigação filosófica é uma relação entre pessoas e as suas ideias, entre as minhas ideias e as dos outros, entre conceitos e formas de os interpretar, entre experiências de pensamento e pensamentos sobre as experiências, entre nós e os outros, nos-otros (KOHAN, 2018) construindo a comunidade: um we (SHARP, 1987). Estar numa comunidade de investigação filosófica permite às crianças e aos adultos que nela participam aperceberem-se dos pontos de vista dos outros, assim como que há pontos de vista diferentes a ter em conta na construção de posições próprias, inaugurando uma racionalidade comunicativa e mergulhando no paradigma da intersubjetividade.

Ann Sharp (1987) refere que a noção de comunidade de investigação filosófica é um conceito extremamente complexo, uma vez que implica uma certa noção de verdade, uma noção de racionalidade e uma certa teoria do bem. Uma 
comunidade de investigação filosófica é uma comunidade de pessoas em relação, de falantes e ouvintes, que dialogam com imparcialidade e coerência na busca da construção da verdade e do bem num processo de autocorreção. À pergunta "porquê adotar o critério da razão uma vez que é tão complicado e trabalhoso?", Sharp (1987) responde que o critério da razão é o caminho para realização da pessoa, para a autonomia, para a criatividade e para o autoconhecimento. É o caminho para a felicidade, entendida como uma vida vivida de acordo com decisões morais aceitáveis.

É convicção de Ann Sharp (1987) que o ambiente de confiança e investigação de uma comunidade de investigação filosófica possibilita que a criança identifique e decida, sob a batuta da razão, como viver melhor, sobre a tolerância e abertura às razões dos outros. A objetividade está no facto de cada posição estar sujeita à avaliação e ao crivo das razões dos outros que fazem comigo a nossa comunidade. Trata-se de uma verdade intersubjetiva, uma verdade conseguida a partir do diálogo, da investigação e da experimentação (imaginemos como seria se...). É uma verdade autocorrigida, sob o compromisso de a construir no diálogo e pelo diálogo. Julgamos encontrar nas afirmações de Sharp uma aproximação à posição de Habermas segundo a qual a intersubjetividade é o acesso a um debate racional sobre a universalização de interesses ou da justificação que ocorre num horizonte fora da vida historicamente concreta ou de uma vida de conduta individual (1983, p. 212-213).

Mas, como afirmámos, a noção de comunidade de investigação filosófica tem percorrido um caminho de aprofundamento de acordo com a noção de intersubjetividade. David Kennedy repensa-a e permite que compreendamos que o conceito, para além de complexo, está em movimento, modificando a experiência e sendo modificado por ela. Multiplica-se, diríamos.

Kennedy (1994) refere não uma comunidade, mas várias: uma teia, diríamos. O que as une é o facto de se constituírem como expressões de comunicação, processos interativos num corpo convergente de sentidos, de significados. As várias comunidades propostas por Kennedy revelam, entre outras coisas, que o critério da razão, apresentado de uma forma embrionária por Sharp, dá lugar a outros complementares. Se a comunidade da linguagem se aproxima do 
intersubjetividade: um olhar sobre a comunidade de investigação filosófica

modelo de Lipman e encontra ecos no paradigma da intersubjetividade de Habermas, as comunidades do gesto, da mente e do amor, por exemplo, acrescentam dimensões de diálogo e de interação que não se podem dissociar.

A comunidade do gesto salienta que o corpo é, também, uma dimensão da intersubjetividade. Antes de se abrir a boca para dizer algo, a linguagem corporal, o gesto, a comunicação não-verbal já estão a criar sentidos. No corpo, o pensamento expressa-se, dá conta de acordos e desacordos, espanto, dúvida, incerteza, desconfiança, ponderação, entre outros, antes mesmo de se tornar palavra. Podemos perceber que o conceito de intersubjetividade ganha volume e permite aberturas a outras formas de comunicação que não somente a dimensão discursiva.

A comunidade da mente revela uma errância contínua entre a decisão e o pensamento disciplinados pelas leis da lógica clássica aristotélica (identidade, não contradição e terceiro excluído), às quais nos submetemos voluntariamente, e a emergência de novas ideias impregnadas das dimensões estética e emocional para além da dimensão estritamente lógica. A multiplicidade de dimensões envolvida acarta uma vulnerabilidade a uma certa desordem. Fala-se dos argumentos "perdidos" que requerem o caminho autocorretivo para que avancem. Talvez a comunidade da mente precise, mais do que qualquer outra, da coragem de uma certa disciplina brincalhona, seguindo o argumento até onde ele nos levar (LIPMAN, 1997, p. 7) num inevitável jogo entre conflitos e perspetivas. A comunidade da mente implica abrir fendas, estabelecer pontes, avançar e recuar através de processos de análise e síntese entre o que é e o que pode ser (KENNEDY, 1994, p. 7).

Numa comunidade de amor estabelecem-se relações afetivas entre os participantes, podem até ocorrer manifestações de ciúme, por exemplo, mas que concebem oportunidades para a emergência de uma espécie de todo, uma espécie de equilíbrio entre experiências individuais que ecoam e se completam na experiência em comunidade e vice-versa (novamente, o sujeito coletivo). É uma comunidade de cuidado baseada numa relação de cuidados. A racionalidade pode ser entendida como uma forma de amor, uma busca de sentido, de significados das semelhanças e das diferenças. A afirmação de Kennedy (1994, p. 6), segundo a qual todas as pessoas tem um desejo natural, uma espécie de curiosidade para 
ampliar os seus conhecimentos sobre pessoas e coisas, será uma outra forma de afirmar que há uma disposição cooperativa para o entendimento, como diria Habermas. Percebemos que a procura de sentidos vale mais quando a partilhamos, que ganha grandeza sempre que deixa de ser solitária e que pode granjeia outros e novos contornos porque está em diálogo numa situação de racionalidade comunicativa.

A passagem da dimensão de uma razão autónoma centrada no sujeito para a dimensão de uma racionalidade comunicativa preconizada por Habermas, possibilita movimentos de pensamento que potenciam novos contornos e possibilidades que se descobrem e inventam para velhos conceitos e velhas ideias.

Um novo movimento do conceito de comunidade de investigação filosófica está presente na noção de "círculo do pensar" de Giuseppe Ferraro (2018). De acordo com este autor, quando estamos em comunidade trabalhamos em círculo para que ninguém se torne invisível e todos tenham o espaço adequado para que todas a vozes se ouçam e cheguem a cada um dos participantes. Este espaço circular não pode ser demasiado pequeno nem demasiado grande. Talvez possamos afirmar que as dimensões exatas que possibilitam as condições para a ação comunicativa e que só se conseguem em círculo. É um círculo do pensar porque dá lugar à prática da filosofia. A filosofia não é saber de alguma coisa, mas saber da coisa, isto é "ver aquilo que falta naquilo que é, para que aquilo que é seja realmente aquilo que é" (2018: 28). O círculo do pensar de Guiseppe Ferraro é um espaço cheio de tempo: um lugar.

Um lugar é onde se troca tempo, diz este autor. Todos têm a palavra quando sentem, quando devem fazer uso dela, sem imposição, ninguém é deixado de lado (postulado da igualdade discursiva). O círculo do pensar é mantido por laços de philía. Tratam-se de laços familiares, sem ser de família. A metáfora da família aplicada ao círculo do pensar é desadequada porque sugere uma organização hierárquica entre os membros da família. Os laços de filiação do círculo do pensar transportam a ideia de relação entre pares que se amparam, porque o amigo é aquele que te sustenta no teu ser, o outro que me torna outro, não igual a si, igual áquilo que sou. É um cuidar para que os outros cuidem de si. Participam todos e segundo o que é importante naquele momento, desviando-se, 
intersubjetividade: um olhar sobre a comunidade de investigação filosófica

tomando novas estradas, se for o caso. Podem ser caminhos já percorridos ou caminhos inexplorados. Também o pensar pode ser um círculo, na medida em que o que se pensa percorre um caminho que passa pelo outro e retorna de uma maneira diferente, com vontade de sair para mais rodada.

Num círculo do pensar acontecem muitas coisas em simultâneo: fala-se, pergunta-se, escuta-se, escreve-se, lê-se, desenha-se, dramatiza-se, joga-se, ... vivese, troca-se tempo (FERRARO, 2018, p. 48). Há a busca e a construção de sentido, de sentidos. As ideias, os pensamentos são vividos, não são verdadeiros ou falsos, bons ou maus, antes emocionantes, maravilhosos, imaginativos, valiosos. Não se trata de questionar qualquer espécie ou definição de verdade dos pensamentos antes o seu sentido, do seu sentido para a comunidade.

É pela partilha dialógica que se revela uma espécie de tensão no interior de um pensamento que julgávamos só nosso e que, ao ser compartilhado, percebemos que já tinha sido antes considerado por outros, mesmo que esses outros sejam longínquos.

A dimensão do cuidado está presente nas abordagens que Sharp, Kennedy e Ferraro fazem ao conceito e à experiência de diálogo filosófico em comunidade. Como vimos, comunidade pressupõe cuidado: cuidado no processo de investigação, cuidado de uns pelos outros como pessoas, cuidado pelas tradições herdadas, cuidado pelas criações do outro. Portanto, existe uma componente afetiva no desenvolvimento de uma comunidade de investigação filosófica que não pode ser subestimada (LIPMAN, 2003, p. 266).

Uma comunidade de investigação filosófica segundo Sharp e Kennedy, um círculo do pensar, de acordo com Ferraro, é também um conjunto de movimentos internos, de aproximação dos membros uns aos outros. Numa fase inicial, crianças e adultos podem partir de uma posição de cooperação na qual obedecem às regras da investigação porque querem ganhar mérito, onde o que importa são as minhas ideias, as minhas conquistas, o meu progresso, talvez uma razão centrada no sujeito. Contudo, com o tempo, a comunidade ganha identidade e aproxima-se de uma posição na qual considera a investigação um processo colaborativo. Quando crianças e adultos de uma comunidade colaboram autenticamente, o que importa é o nós e não o sucesso pessoal. O que importa são as nossas ideias, as nossas 
conquistas, o nosso progresso. Esta transição para o "nós" é um processo de maravilhamento porque as crianças e adultos sabem que a comunidade passa a ter um grande significado para elas. A felicidade de uns e outros é tão importante como a sua e há real cuidado entre todos. Este cuidado capacita para conversar de um modo distinto porque os participantes podem envolver-se na investigação sem medo ou receio de humilhação. Como afirmava A. Sharp (1987), significa exteriorizar ideias que nunca tinham sido pensadas ou expressas antes, só para ver o que acontece.

Compreender que se está numa comunidade de investigação filosófica é reconhecer que se está numa relação intersubjetiva. Isto é, cultiva-se uma racionalidade comunicativa como modo de incluir o outro e a sua alteridade nos nossos processos de pensamento e desenvolve-se uma atitude de expansão de horizontes e intenções, espírito de comunidade. É um valorizar e agir (WEBER, 2008).

Para além disso, é necessário reconhecer que todos os participantes têm a mesma liberdade e possibilidade de tomar da palavra, pedir razões, pedir explicações, concordar e discordar, entre outros. Acrescente-se que aos participantes numa comunidade de investigação filosófica é reconhecido o postulado da sinceridade (HABERMAS, 2010). Numa palavra, teremos de estar em presença das pressuposições idealizadoras da comunicação.

Pensar em comunidade, lançar as nossas razões ao crivo da comunidade, é dar conta do clima de cuidado, de respeito e confiança que impregna a comunidade de investigação filosófica. A confiança edifica a segurança, nutre o risco da criatividade e estimula a fazer um esforço de seguir no que realmente se pensa. Possibilita a autocorreção e a mudança de ponto de vista quando é caso disso. Confiança, segurança, sinceridade tornam uma comunidade de investigação filosófica num espaço de libertação. Com a filosofia, as crianças libertam-se dos professores e do currículo (SPLITTER \& SHARP, 1995, p. 163-156) e com a atitude investigativa todas as perguntas se fazem, não há assuntos tabus e não há quem tenha razão à partida.

Estas experiências em comunidade assumem uma dimensão relevante na vida das crianças quando são realizadas em continuidade. Gabriela, sete anos, 
intersubjetividade: um olhar sobre a comunidade de investigação filosófica

uma das meninas que participa no projeto de Filosofia para Crianças na Escola Básica e Secundária Armando Côrtes-Rodrigues, afirmava em 2016: “Quem me conhece sabe que eu tenho muita vergonha, sou muito tímida. Mas aqui, nas sessões de filosofia, sinto-me livre." E, dois anos mais tarde, reforçava: "Quando começaram as sessões de filosofia para crianças sentia-me como uma gota de água pequenina no mar, agora sinto que sou uma onda enorme".

A comunidade de diálogo filosófico foi percebida pela Gabriela como um lugar de liberdade, de segurança, de tranquilidade, de empoderamento. A Gabriela parece ter compreendido que, na escola (e na vida), há diferenças entre situações de ação comunicativa e outras onde isso não acontece. Sente-se livre porque sabe que, em comunidade de diálogo filosófico, todos tem a mesma oportunidade de pensar e construir pensamento e este processo é um processo a sério, comprometido, com consequências (postulados da igualdade discursiva e da sinceridade), onde ninguém tem razão à partida. Para além disso, numa comunidade de diálogo filosófico fazem-se experiências de pensamento e constrói-se pensamento sobre a experiência (KOHAN, 2012). A Gabriela verbaliza a força de pertencer a uma comunidade de investigação filosófica e como a sente. E esta é uma experiência sentida pela Gabriela como libertadora.

Tal como acontece com as crianças, também o professor facilitador se liberta numa comunidade de investigação filosófica. $\mathrm{O}$ adulto começa por assumir um papel de facilitador da construção da comunidade e organiza e possibilita o espaço do diálogo filosófico. Habermas (2010) diria que assume uma ação estratégica para possibilitar uma ação comunicativa7. Fazendo a ponte para o contexto de comunidade de investigação filosófica, poder-se-á interrogar se recorrer à ação estratégica para promover a ação comunicativa não será um dos papéis do facilitador. Quando o facilitador coloca uma questão, afirma que uma ideia é interessante e propõe que a comunidade a siga, quando incentiva à justificação da ideia, à clarificação de um pensamento exposto, não estará a recorrer a uma ação estratégica para promover o entendimento mútuo? Kennedy afirma que o

\footnotetext{
7 De modo a promover-se um entendimento mútuo fruto da ação comunicativa que "poderão ser utilizados elementos estratégicos na condição de servirem o objectivo de levar a um entendimento mútuo direto". Parece indiciar que alguém decide recorrer à ação estratégica para promover a ação comunicativa (HABERMAS, 1996, p.10-11, nota de rodapé).
} 
facilitador tem de "ser morto e comido" na medida em que a própria comunidade se apropria e internaliza as suas funções iniciais (2017: 753). No paradigma da intersubjetividade que acarreta uma racionalidade comunicativa, os adultos que participam numa comunidade libertam-se do "seu papel" de facilitador e assumem uma posição de ignorância, de um que investiga, uma certa libertação que conduz à vivência da filosofia numa perspetiva de experiência de pensamento (CUNHA, KRÜGER, LOPES, KOHAN, 2015). O adulto reconstrói a filosofia como uma relação dialógica em processo, interativa, igualitária, um evento de oralidade discursiva, que é sempre como se fosse uma primeira vez, passa de uma razão autónoma centrada no sujeito e na posse do conhecimento para uma racionalidade comunicativa de busca de saber.

O que se passa numa comunidade de investigação filosófica abre, ainda, a possibilidade de se vivenciar uma escola baseada no diálogo, na escolha, na investigação e na vivência da democracia direta. De se abrir um espaço funcional para tomada de decisões partilhadas, de modelo de governança que conduzirá, naturalmente a intervenções no sentido de soluções concretas para problemas práticos quer ao nível local, quer ao nível global (KENNEDY, 2017). Algo semelhante se pode encontrar no pensamento de Habermas (1986) quando afirma que as pessoas em situação de ação comunicativa alcançam consensos racionalmente fundamentados porque estes não se baseiam em relações assimétricas de poder, nem com recurso a posições de autoridade. ${ }^{8}$

Numa sessão sobre o que é medo Fernando, um menino de 10 anos, afirmava: "Eu tenho um medo antigo e outro mais recente. O mais recente é a proposta dos artigos $11 .^{\circ}$ e $13 .^{\circ}$. Temos que investigar o que são os artigos $11 .^{\circ}$ e $13 .^{\circ}$ e perceber como será a escola e o mundo se eles forem aprovados."

\footnotetext{
8 Os consensos enganadores ou distorcidos são os que resultam de relações assimétricas de poder, que são alcançados sob coação. Há uma espécie de recurso a uma posição de autoridade quando, por exemplo, alguém concorda em fazer algo porque uma autoridade ou especialista lhe apresentou um conhecimento que tem e que lho explicou. $\mathrm{O}$ acordo alcançado, neste caso, não é verdadeiramente um consenso racionalmente fundamentado, antes um consenso distorcido por uma relação assimétrica ou de dominação. Alguém sabe e explica a verdade a um outro que não a tem e, por essa razão, concorda com ela (HABERMAS, 1986a).

$9 \mathrm{O}$ menino referia-se à proposta do Parlamento Europeu que, em 2018, pretendia atualizar a regulamentação sobre os direitos de autor no contexto da Internet. Os artigos $11 .^{\circ}$ e $13 .^{\circ}$ referem-se especificamente a normas que determinam que plataformas online, independente de tamanho ou
} 
intersubjetividade: um olhar sobre a comunidade de investigação filosófica

Nesta situação concreta, a comunidade abraçou uma dimensão política e sentiu a necessidade e a possibilidade de poder intervir no espaço público. $\mathrm{O}$ Fernando deu voz a um problema atual e lançou a comunidade na investigação de possíveis consequências para a vida da escola (local) e do mundo (global), analisando razões, exemplos, contraexemplos, avaliando prós e contras, medos antigos e novos e pensando em formas de intervenção e soluções concretas para os problemas levantados. Introduzir comunidades de investigação na escola leva-nos a pensar sobre a natureza da própria escola e dos mundos que queremos construir e em que queremos viver.

\section{considerações quasi-finais}

Ao analisarmos a dimensão intersubjetiva da prática da comunidade de investigação filosófica demo-nos conta que é possível verificar a passagem de uma autonomia da razão centrada no sujeito, um pensar por si mesmo, para a prática de uma racionalidade comunicativa, centrada num pensamento em comunidade. Os pressupostos inevitáveis da comunicação fundam e mantêm as comunidades e permitem o clima de confiança e de cuidado que possibilitam que os membros da comunidade pensem livremente e se deixem guiar pela força do we, do nós, do nos-otros. O paradigma da intersubjetividade preconizado por Habermas fundou uma forma de chegar a consensos racionalmente fundamentados. Hoje, a sua obra aponta para a ideia de que o que mantém as pessoas numa atitude de ação comunicativa são as forças da fundamentação racional e da motivação racional.

Não é somente em contexto de comunidades de investigação filosófica que se averiguam as potencialidades do paradigma da intersubjetividade de Habermas, é certo. Também na discussão entre especialistas podemos encontrar essas potencialidades. Foi, em certa medida, o que conseguimos investigar nas diferentes abordagens de Sharp, Kennedy e Ferraro. O diálogo estabelecido entre os filósofos e o conceito de comunidade de investigação filosófica, os argumentos e formas de concretização do diálogo filosófico em comunidade dão conta da fecundidade da racionalidade comunicativa. Sabemos que o conceito de

do tipo de serviço oferecido, filtrem uploads de conteúdo para combater a violação de copyright por parte dos usuários. 
comunidade de investigação filosófica, tal como é pensado e vivido por Ann Sharp, é distinto do conceito de comunidade de investigação filosófica de Kennedy. Percebemos que o círculo do pensar de Ferraro é uma outra abordagem ao pensamento filosófico em comunidade. Pensamos, no entanto, que estas abordagens entram em diálogo e fazem-no, em boa medida, porque isso é permitido pelo movimento de uma racionalidade comunicativa.

O caminho percorrido entre a comunidade de investigação filosófica entendida como espaço de intersubjetividade (SHARP, 1987), passando pela abertura da comunidade de investigação filosófica a outras dimensões não discursivas da comunicação (KENNEDY, 1994) e avançando para o círculo do pensar que enche o espaço de tempo e o torna num lugar (FERRARO, 2018), revelam como a comunidade de investigação filosófica é um conceito e uma experiência abertos e fecundos.

De acordo com as perspetivas de Sharp \& Splitter, Kennedy e Ferraro, podemos compreendemos que o diálogo filosófico em comunidade traz consigo diferentes abordagens acerca do que é a filosofia e o filosofar, a relação entre a filosofia e a escola, a relação entre crianças e adultos. Estas possibilidades de diálogo dão-se no pressuposto de uma relação intersubjetiva também entre conceitos, experiências e pensamentos sobre os conceitos e as experiências.

Julgamos que as pressuposições inevitáveis da comunicação de Habermas contribuem para transformar um espaço de intersubjetividade preconizado por Ann Sharp e David Kennedy num lugar onde se troca e se doa tempo, como explica Ferraro. O contributo de tais pressuposições inevitáveis da comunicação reside no reconhecimento de uma disposição cooperativa para o entendimento que assenta na força da fundamentação racional - postulado da igualdade discursiva - e na força da motivação racional - postulado da sinceridade. São, talvez, estas algumas das razões que justificam o que levará alguém a abdicar da supremacia da razão autónoma em favor de uma razão comunicativa.

Sabemos que nas suas obras Habermas não se refere às crianças. Então, que lugar há para a infância nesta racionalidade comunicativa? Esta é, talvez, uma nova questão, um novo desafio à própria racionalidade comunicativa. 
intersubjetividade: um olhar sobre a comunidade de investigação filosófica

Certo dia de 2018, a Clara, de oito anos, afirmou: "A filosofia é uma espécie de manipulação do cérebro." A declaração desafiou-nos: o que quereria dizer a menina? Que os conceitos, as experiências, as ideias são para manipular, para manusear? Talvez seja o que estamos a fazer com o conceito de intersubjetividade, convocando a racionalidade comunicativa e a ação comunicativa para lançar novos olhares ao diálogo filosófico em comunidade. Talvez a Clara queira dizer que os conceitos, as experiências, as ideias têm elasticidade e fendas. Por vezes são esticados e encolhidos, tomam outras formas. Por vezes quebram e dividem-se. Por vezes são resilientes. Por vezes escapam pelas fendas, escorregam e fogem. São ideias que se têm e depois faz-se com elas o que se pode.

\section{referências}

COOKE, Maeve. Language and Reason. A Study of Habermas's Pragmatics. Cambridge: The MIT Press, 1994.

CUNHA, E. KRÜGER, J. LOPES, S. KOHAN, Walter. Por amor à filosofia... e ao mundo que se abre com ela. Revista Digital de Ensino de Filosofia, Santa Maria, v. 1, n.1, p. 80103, 2015.

FERRARO, G. A escola dos sentimentos. Da alfabetização das emoções à educação afetiva. Rio de Janeiro: NEFI, Coleção Ensaios, 2018.

FLETCHER, N. Shared Autonomous Reasoning: Interpretations of Habermasian Discourse for the Community of Philosophical Inquiry. Revista Analytic teaching and philosophical praxis, v. 37, n. 1, p. 46-62, 2016.

HABERMAS, J. O discurso filosófico da modernidade. Alfragide: Publicações Dom Quixote, 1985.

HABERMAS. J. 1. 'Rationality' - A Preliminary Specification. in The Theory of Communicative Action. Reason and the Rationalization of Society. v. 1. Cambrigde: Polity Press, p. 8-42, 1986.

HABERMAS, J. Capítulo III - Notas programáticas para a fundamentação de uma ética do discurso. Ponto 2 - O princípio da universalização como regra de argumentação. in Consciência Moral e Agir Comunicativo. Rio de Janeiro: Tempo Brasileiro (tradução de Guido A. De Almeida), p. 78-131, 1989.

HABERMAS. J. Racionalidade e Comunicação. Lisboa: Biblioteca de filosofia contemporânea, Edições 70, 1996.

HABERMAS, J. Between Naturalism and Religion. Cambridge: Polity Press, 2008.

HABERMAS, J. Capítulo 5. Teorias da verdade. in Teoria da Racionalidade e Teoria da Linguagem, v. II. Lisboa: Edições 70, p. 181-233, 2010

KENNEDY, D. The Five Communities. Revista Analytic Teaching, v. 15, n. 1, p. 3-15, 1994.

KENNEDY, D. The Philosopher as Teacher. The Role of a Facilitator in a Community of Philosophical Inquiry. Revista Metaphilosophy, v. 35, n. 5, p. 744-765, 2004.

KENNEDY, N. \& KENNEDY, D. Community of philosophical inquiry as a discursive structure, and its role in school curriculum design. in N. Vansieleghem and D. Kennedy (eds.), Philosophy for children in transition: Problems and prospects. London: Blackwell, p. 97-116, 2012.

KENNEDY, D. KENNEDY, N. Community of philosophical inquiry online and off: retrospectus and prospectus. in AKYOL, Z.; GARRISON, D. R. A Educational 
Communties of Inquiry: Theoretical Framework, Research and Practice. Hershey, Pensilvânia: Editora IGI Global, p. 12-29, 2013.

KENNEDY. D. An Archetypal Phenomenology of Skolé. Revista Educactional Theory, v. 67, n. 3, p. 273-290, 2017.

KOHAN, W. Palavras, passos e nomes para um projeto. in W. Kohan and B.F. Olarieta (org.) A escola pública aposta no pensamento. São Paulo: Gutenberg, p. 13-49, 2012.

KOHAN, W. A música da amizade: notas entre filosofia e educação. Revista Educação (UFSM), v. 43, n. 2, p. 27-38, 2018.

LIPMAN, M. Good Thinking. Revista Inquiry: Critical Thinking Across the Disciplines, v. 15, n. 2, p. 37-41, 1995.

LIPMAN, M. Thinking in Community. Revista Inquiry: Critical Thinking Across the Disciplines, v. 16, n. 4, p. 6-21, 1997.

LIPMAN, M. GARCIA MORYIÍN. Matthew Lipman: uma biografia intelectual. Haser Revista Internacional de Filosofía Aplicada, v. 2, p. 177-200, 2011.

LIPMAN, M. Thinking in Education. Cambridge: Cambridge University Press, 2003.

MIRANDA ALONSO, T. Accion Comunicativa Y Processo Educativo: J. Habermas y M. Lipman. Ensayos: Revista de la Facultad de Educación de Albacete, v. 2, p.33-46, 1991.

SHARP, A. What is a community of inquiry? in Journal of Moral Education. v. 16, n. 1, p. 37$45,1987$.

SPLITTER, L. SHARP, A. La outra educación. Filosofia para Ninös y la comunidade de indagación. Buenos Aires: Manantial, 1995.

VANSIELEGHEM, N. KENNEDY, D. What is Philosophy for Children, What is Philosophy with Children - After Matthew Lipman?. In Journal of Philosophy of Education, v. 45, n.2, p. 172-182, 2011.

WEBER, B. J. Habermas and the Art of Dialogue: The Practicability of the Ideal Speach Situation. in Analytic Teaching, v. 28, n. 1, 2008. Disponível em: <http:/ /libservices.viterbo.edu/journal/ojs/index.php/at/article/view/856>. Acesso em: 3 out. 2017.

recebido em: 02.05.2019

aprovado em: 06.05.2019 